\title{
A Comparative Study of Burnout, Stress, and Resilience among Emotional Workers
}

\author{
Yu-Ri Lee ${ }^{1,2}$, Ju-Yeon Lee ${ }^{2,3}$, Jae-Min Kim³, II-Seon Shin'³, Jin-Sang Yoon ${ }^{3}$, and Sung-Wan Kim ${ }^{2,3} \bowtie$ \\ ${ }^{1}$ Department of Social Welfare, Nambu University, Gwangju, Republic of Korea \\ ${ }^{2}$ Gwang-ju Mental Health and Welfare Commission, Gwangju, Republic of Korea \\ ${ }^{3}$ Department of Psychiatry, Chonnam National University Medical School, Gwangju, Republic of Korea
}

\begin{abstract}
Objective To investigate associations between stress, resilience, and burnout in three emotional job sectors.
Methods We conducted a multi-group comparative study using structural equation modeling and latent mean analysis. In total, 806 participants (403 call center consultants, 270 mental health workers, and 133 school counselors) completed self-administered questionnaires including the Perceived Stress Scale, Korean version of the Connor-Davidson Resilience Scale, and Maslach Burnout InventoryGeneral Survey.

Results Stress had significant direct effects on resilience and burnout, and resilience had significant direct effects on burnout in all groups. Resilience partially mediated these relationships among call center consultants and school counselors. Stress and burnout were highest in call center consultants, followed, in order, by mental health workers and school counselors. Resilience was highest in school counselors, followed, in order, by mental health workers and call center consultants. The effect size of the latent mean difference was highest for burnout, followed, in order, by resilience and stress.

Conclusion Our findings suggest that stress caused by emotional labor can contribute to burnout. Interventions targeted at different sectors are needed to reduce burnout.

Psychiatry Investig 2019;16(9):686-694
\end{abstract}

Key Words Burnout, Stress, Resilience, Mental health, School.

\section{INTRODUCTION}

As the scope of human service fields has expanded, the expression of emotions, such as hospitality and kindness, have emerged as critical in service industries. ${ }^{1}$ Emotional workers are not allowed to express their actual emotions during work but are required to control or adapt their behaviors, including their verbalizations, body language, and facial expressions, according to the rules and expectations associated with their job. ${ }^{1}$ In the process of meeting people's requirements, emotional laborers are commonly expected to follow positive emotional display rules, that is, to express positive feelings, and to suppress negative feelings despite customers' unfair

\footnotetext{
Received: April 28, 2019 Revised: June 24, 2019

Accepted: July 10, 2019

$\triangle$ Correspondence: Sung-Wan Kim, MD, PhD

Department of Psychiatry, Chonnam National University Medical School, 160 Baekseo-ro, Dong-gu, Gwangju 61469, Republic of Korea

Tel: +82-62-220-6148, Fax: +82-62-225-2351, E-mail: swkim@chonnam.ac.kr

(ac) This is an Open Access article distributed under the terms of the Creative Commons Attribution Non-Commercial License (https://creativecommons.org/licenses/bync/4.0) which permits unrestricted non-commercial use, distribution, and reproduction in any medium, provided the original work is properly cited.
}

and negative requests; as such, these laborers experience emotional dissonance. ${ }^{2,3}$ Thus, the rate of burnout from emotional labor is increasing, and the number of emotional laborers experiencing mental health issues as well as physical health problems is dramatically rising. ${ }^{4}$ Jobs that involve a high level of emotional labor have been reported to include sales, healthrelated or medical jobs, and social welfare jobs; $;, 5$ therefore, this research focuses and elaborates specifically on call center consultants in the sales job sector, and on mental health-related workers in the health, medical, and social welfare job sectors. Moreover, although they belong to the education job group, known to have a relatively lower level of emotional labor, school counselors will be discussed in the research as professionals who help students with mental health problems and who confront emotional labor issues.

Among call center consultants, psychological problems rooted in the nature of their job are increasing; a call center consultant is frequently exposed to anger, hostility, and verbal violence, in addition to the basic expectations of consultants, which are to provide customers with information and meet their needs. ${ }^{4,8}$ The mental health-related job sector is a field 
with a multi-disciplinary team approach, and mental health workers experience aggravating symptoms of emotional exhaustion and depression, as the nature of the jobs requires them to focus on facing clients with mental health problems and relieving the latter's negative emotions. ${ }^{9,10}$ Lastly, school counselors respond sensitively to students' verbal and non-verbal expressions, and, in turn, communicate appropriate emotions during counseling sessions; such behaviors lead to emotional exhaustion deriving from emotional dissonance. ${ }^{7,11}$

Therefore, it is critical to understand the seriousness of the problems resulting from emotional labor and to provide interventions to prevent burnout. Differentiated intervention strategies should also be identified. However, comparative studies of different jobs involving emotional labor have been absent. Thus, this research intends to extend the scope of previous research examining simple linear correlations with respect to each emotional job sector, by conducting a multigroup comparative study specifically on call center consultants, mental health workers, and school counselors. Specifically, burnout, stress, and resilience were selected as major variables, because stress is reported as a risk factor for burnout, ${ }^{12,13}$ while resilience is a protective factor against burnout $^{14-18}$ Using structural equation modeling (SEM), direct and indirect effect analyses were performed; latent mean analysis (LMA) was used to compare latent mean differences between the major variables among the three job groups. Our research hypotheses were as follows: 1) Stress directly affects burnout, 2) Resilience directly affects burnout, 3) Resilience mediates the relationship between stress and burnout, 4) There will be latent mean differences in the major variables among the three job groups.

\section{METHODS}

\section{Participants}

Cross-sectional surveys were conducted from September 2015 to May 2016 by researchers from the Gwangju Mental Health Commission and Gwangju Metropolitan Mental Health and Welfare Center, who visited participants' work or training venues. Self-administered questionnaires were delivered to 403 call center consultants working at 1 of 12 customer service centers, 270 mental health professionals working at community mental health centers, and 133 school counselors in Gwangju. All participants completed the surveys, which were filled out anonymously to protect respondents' privacy. The study was approved by the Institutional Review Board of Chonnam National University (CNUH-2015-171; 172).

\section{Measures}

Perceived stress was measured using the Perceived Stress
Scale, which consists of ten items measuring specific feelings experienced in the past one month. ${ }^{19,20}$ In the research, out of the ten items from the original study, only five items that had communality values higher than 0.4 in exploratory factor analysis and squared multiple correlation (SMC) values higher than 0.4 in confirmatory factor analysis ${ }^{21}$ were used to measure perceived stress. The scale comprises five items for: "overwhelmed by an unpredicted, flustering situation," "loss of ability to control," "experience hypersensitivity," "experience anger due to a loss of control," and "experience frustration and helplessness from work." The respondents were asked to rate the items on a five-point Likert scale, ranging from 0 to 4 , with higher scores indicating greater psychological stress. Regarding, the scales reliability, Cronbach's $\alpha$ was 0.832 .

Resilience was measured using the Korean version of the Connor-Davidson Resilience Scale (K-CD-RISC), which consists of 25 items measuring resilience as an ability to cope with stress successfully. ${ }^{22}$ Out of the 25 items from the K-CDRISC, we applied 12 items that had communality values higher than 0.4 in exploratory factor analysis and SMC values higher than 0.4 in confirmatory factor analysis. ${ }^{21}$ The items were then categorized as three sub-factors: hardiness, optimism, and patience. Then, respondents were asked to rate the items on a five-point Likert scale, ranging from 0 to 4 , with higher scores indicating greater resilience. Regarding, the reliability of the scale, Cronbach's a was 0.858 .

Burnout was measured using the Maslach Burnout Inventory-General Survey (MBI-GS), which contains three dimensions: exhaustion, cynicism, and professional efficacy. ${ }^{23} \mathrm{We}$ used a 10-item burnout scale for measuring emotional exhaustion and cynicism so as to focus on assessing emotional burnout based on emotional labor work. Regarding, the reliability of the scale, Cronbach's a was 0.749 .

\section{Statistical analyses}

To analyze the data for this research, SPSS 20.0 and AMOS 20.0 (SPSS Inc., Chicago, IL, USA) were used. Exploratory and confirmatory factor analyses were conducted. To measure the scales' reliability, Cronbach's a values were calculated. Descriptive statistics, such as frequencies, means, standard deviations, and normality analyses, were also derived. For the comparative analysis of direct and indirect effects, SEM was conducted. To assess the goodness of fit, indices such as $\chi^{2}$, comparative fit index (CFI), Tucker Lewis index (TLI), and root mean square error of approximation (RMSEA) were used. Moreover, LMA using controlled latent variables without measurement errors was conducted. ${ }^{24,25}$ To validate the relative effect of the latent mean, Cohen's effect size was used. 


\section{RESULTS}

\section{Socio-demographic and emotional labor-related characteristics of participants}

The socio-demographic characteristics of participants are described in Table 1. Most participants (88.7\%) were female. About $70 \%$ of school counselors were above 40 years of age, while in other two groups less than $30 \%$ were above 40 years of age. All participants of mental health workers and school counselors graduated from a university or graduate school and $22.9 \%$ of call center consultants graduated from a high school.

About $72 \%$ of call center consultants received verbal threats from clients and 30\% experienced sexual harassment from clients. Although $65.8 \%$ of consultants felt the need to receive counseling from a psychological counselor, professional counselors were available only in $14.1 \%$ of centers. Among mental health workers, $72.6 \%$ experienced verbal threats, $33.7 \%$ received physical threats, and $18.9 \%$ experienced sexual harassment from patients. Furthermore, 33.3\% suffered from emotional sequelae from patients' suicide attempts. Among school counselors, 33.8\% experienced verbal threats, $15.8 \%$ had physical threats, and $12.0 \%$ experienced sexual harassment by students. Furthermore, $27.8 \%$ experienced verbal threats from guardians, and $53.4 \%$ suffered from emotional sequelae from students' suicide attempts.

\section{Descriptive statistics of measurement variables}

In SEM, if measurement variables do not have normal distributions, the assumption of multivariate normality is not met. The wrong estimates produced prevent proper statistical

Table 1. Sociodemographic characteristics of emotional laborers

\begin{tabular}{lccc}
\hline & $\begin{array}{c}\text { Call center } \\
\text { workers } \\
(\mathrm{N}=403)\end{array}$ & $\begin{array}{c}\text { Mental health } \\
\text { workers } \\
(\mathrm{N}=270)\end{array}$ & $\begin{array}{c}\text { School } \\
\text { counselors } \\
(\mathrm{N}=133)\end{array}$ \\
\hline Gender (\%) & $28(7.0)$ & $56(20.7)$ & $7(5.3)$ \\
$\quad$ Male & $375(93.0)$ & $214(79.3)$ & $126(94.7)$ \\
Female & & & \\
Age, years (\%) & $67(16.6)$ & $82(30.3)$ & $17(12.8)$ \\
$20-30$ & $242(60.1)$ & $112(41.6)$ & $22(15.5)$ \\
$31-40$ & $94(23.3)$ & $76(28.1)$ & $94(70.7)$ \\
$\geq 41$ & & & $108(81.2)$ \\
Marital status (\%) & $261(64.8)$ & $151(51.9)$ & $25(18.8)$ \\
Married & $142(35.2)$ & $119(44.1)$ & \\
$\quad$ Not married & & & - \\
Educational level (\%) & & & \\
High school & $92(22.9)$ & & \\
University & $308(76.4)$ & $211(78.1)$ & $46(34.6)$ \\
Graduate school & $3(0.7)$ & $59(21.9)$ & $87(65.4)$ \\
\hline
\end{tabular}

testing. Considering the conditions of normality (skewness lower than 2, kurtosis lower than 7) in SEM, ${ }^{26}$ the chosen variables were proven to meet the basic requirement levels of skewness and kurtosis (Supplementary Table 1 in the onlineonly Data Supplement).

\section{Comparative analyses from SEM}

\section{Direct effects analyses}

In the research, we tested goodness of fit based on CFI, TLI, and RMSEA, which are not sensitive to sample size and have established evaluation criteria that consider simplicity. The goodness of fit of the study model was satisfactory for all indices, except for $\chi^{2}$ (Figure 1, Table 2).

In all groups (we had three groups in the survey: call center consultants, mental health workers, and school counselors), the results indicated that stress had a significant direct effect on resilience and burnout, and resilience had a significant direct effect on burnout (Table 2).

Gender, marital status, age, and educational level were controlled. These control variables had some significant influence on the major variables (Figure 1, Table 2).

\section{Indirect effects analysis}

Significance testing of indirect effects was performed using the bootstrapping method. The analysis of the stress-resilience-burnout path showed that for the call center consultants $(\beta=0.138, p=0.002)$ and school counselors models $(\beta=0.147, p=0.008)$, the partial mediating effect of resilience was significant, but for the mental health workers model ( $\beta=0.084, p=0.116)$, the indirect effect of resilience was not significant (Table 2).

\section{Comparative analyses based on LMA}

LMA has an advantage of taking measurement errors into account between each variable compared with ANOVA, which directly compares the variables. ${ }^{27}$ To perform LMA, the configural, metrics, and scalar invariances of the model were validated. ${ }^{28}$ The results are given as follows.

\section{Invariance analysis}

The first validation is for configural invariance. This is a step to validate if measurement variables load on the same factors for each group. In both comparative models, configural invariance was validated at a significant level (Table 3).

The second step is the validation of metrics invariance. We compared the $\chi^{2}$ value and degree of freedom to identify if the metrics invariance, which puts invariance restrictions on factor coefficients, and the configural invariance, which puts any invariance restrictions, had a significant difference. In the 


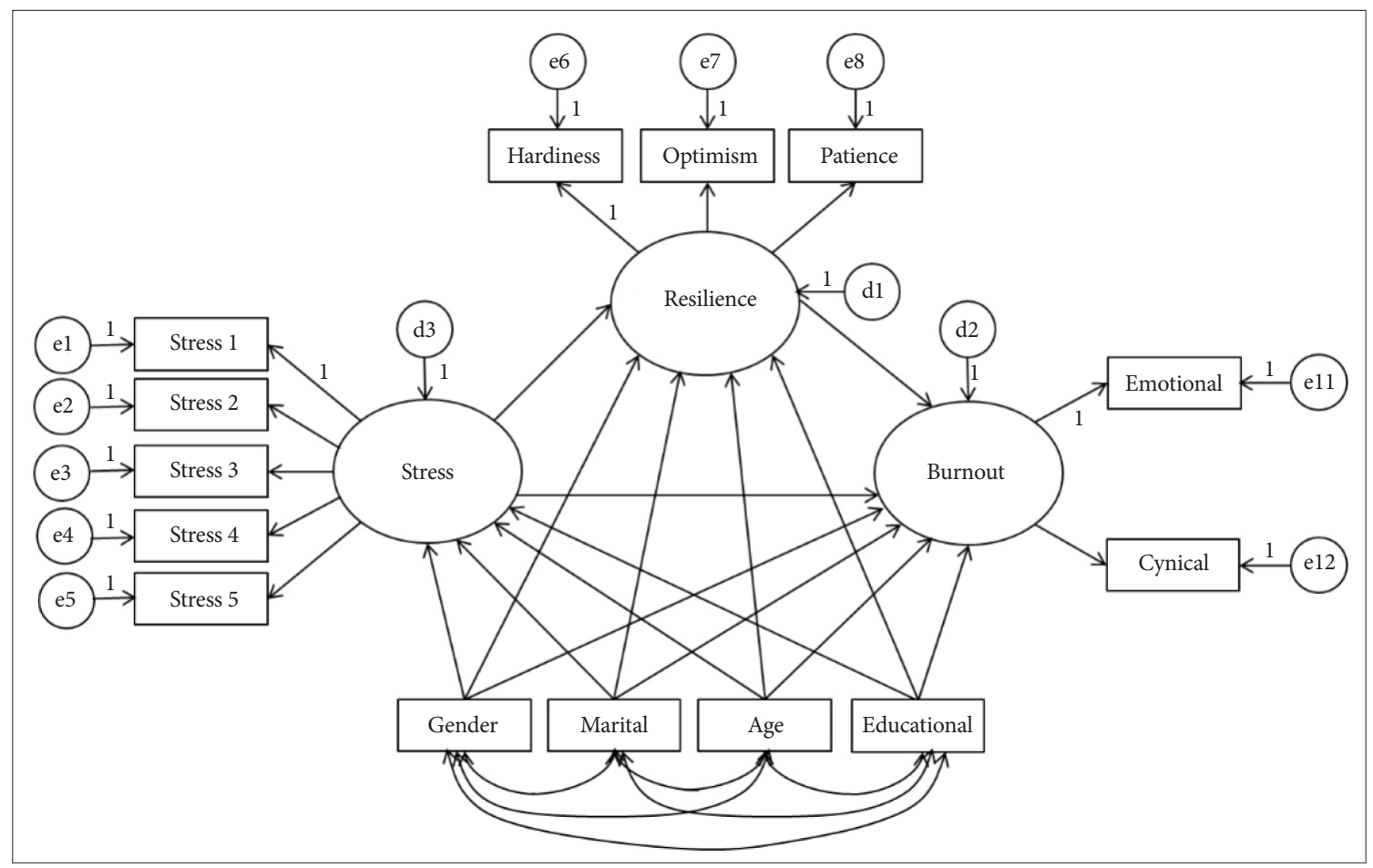

Figure 1. Study model. e: measurement error, d: unexplained error.

three comparative analysis models, the difference between the $\chi^{2}$ values of metrics and configural invariances was not statistically significant at the $95 \%$ confidence level, and the indices of TLI, CFI, and RMSEA did not worsen; as such, the conditions of metrics invariance were all met (Table 3). ${ }^{29,30}$

The third step is the validation of scalar invariance. In scalar invariance, invariance restrictions are placed on the intercepts of each measurement variable. As given in Table 3, in all of the three comparative analysis models, the differences of the $\chi^{2}$ value of metrics and scalar invariances were statistically insignificant at the $95 \%$ confidence level, ${ }^{29}$ and the indices of TLI, CFI, and RMSEA did not worsen, ${ }^{30}$ meeting the conditions of scalar invariance (Table 3).

\section{LMA}

As the mean value of factors cannot be directly compared in LMA, the latent mean of a reference group should be fixed to 0 to predict the latent means of other groups. ${ }^{25,28}$ The results are given in Table 4 .

Moreover, Cohen's effect sizes (d) ${ }^{31}$ were calculated to evaluate the degree of mean differences of the latent variables. According to Cohen's criteria, if $\mathrm{d}$ is lower than 0.2 , the difference is considered small; if $d$ is equal to 0.5 , the difference is moderate; and if $\mathrm{d}$ is more than 0.8 , the difference is considered large. To calculate the effect size, common standard deviations must be calculated, and for this, factor variance invariance indicating the same latent variable deviations from the two groups should be obtained. ${ }^{29}$ The $\chi^{2}$ difference test on scalar invariance, for all three comparative analysis models, showed insignificant differences at the $95 \%$ confidence level, meeting the criteria for factor variance invariance (Table 3). Therefore, the effect sizes were calculated by deriving common standard deviations from each group (Table 4).

In the mental health related worker-call center consultant comparative model, while the call center consultants' stress and burnout were higher than those of the mental health workers, their resilience turned out to be low. The effect sizes indicated that stress was moderate, resilience was high, and burnout was considerably high. In the mental health workerschool counselor comparative model, while the mental health workers' stress and burnout levels were generally higher than those of the school counselors, the mental health workers' resilience was lower. The effect sizes showed that stress was moderate, whereas resilience and burnout were high. In the school counselor-call center consultant comparative model, compared with school counselors, stress and burnout were relatively high for call center consultants, whereas their resilience was low. The effect sizes described the stress as high, and resilience and burnout as considerably high (Table 4).

\section{DISCUSSION}

This research conducted SEM analysis and LMA on the stress, resilience, and burnout in three job sectors known to 


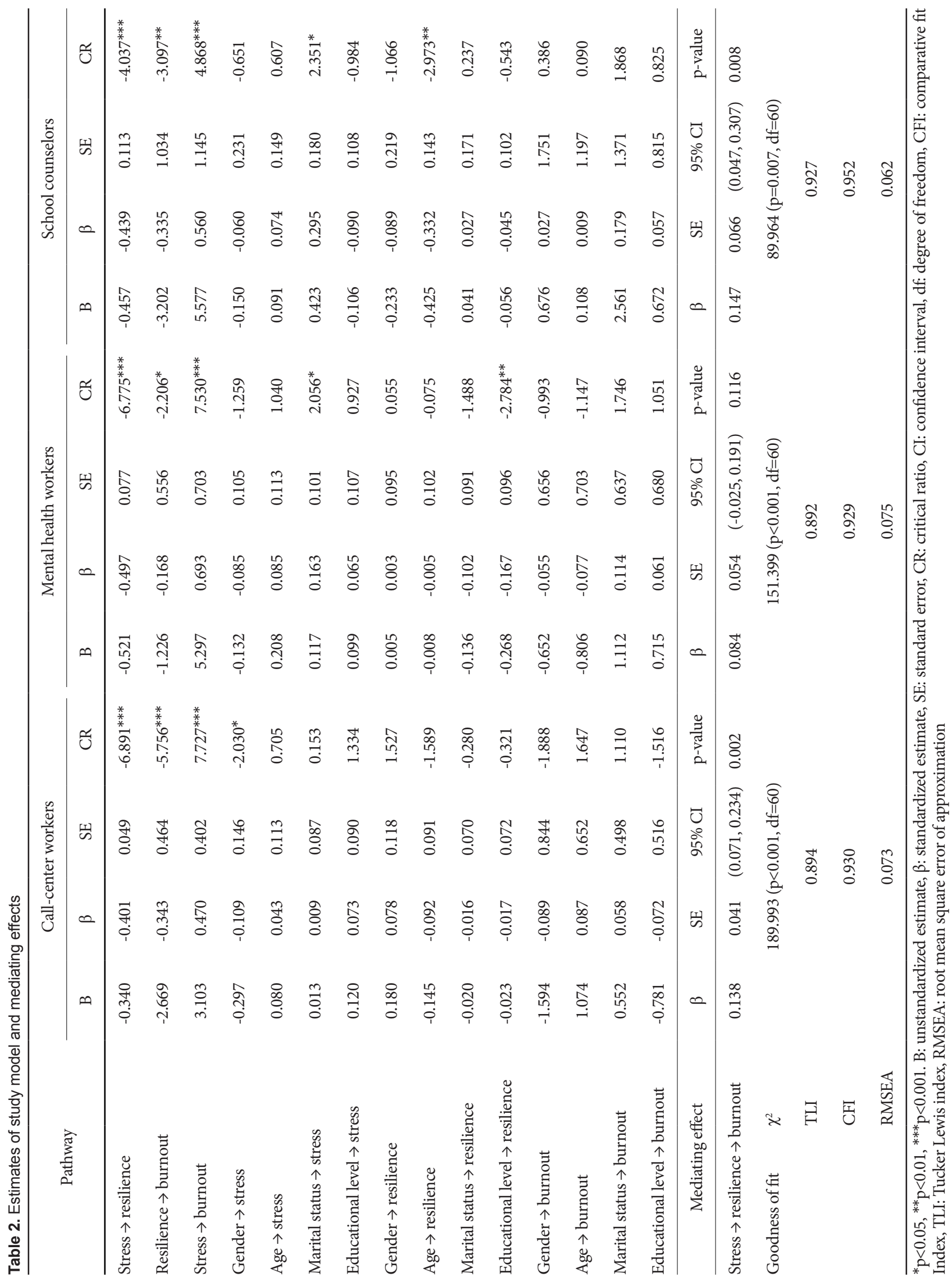


Table 3. Goodness-of-fit index of invariance tests between the three groups

\begin{tabular}{|c|c|c|c|c|c|c|}
\hline & \multicolumn{6}{|c|}{ Goodness-of-fit Index } \\
\hline & $\chi^{2}$ & df & p-value & CFI & TLI & RMSEA \\
\hline \multicolumn{7}{|c|}{ Mental health worker-call center consultant } \\
\hline Configural invariance & 240.572 & 64 & $<0.001$ & 0.932 & 0.952 & 0.054 \\
\hline Metrics invariance & 246.318 & 71 & $<0.001$ & 0.939 & 0.952 & 0.051 \\
\hline Scalar invariance & 253.973 & 78 & $<0.001$ & 0.945 & 0.952 & 0.049 \\
\hline Factor variance invariance & 234.763 & 81 & $<0.001$ & 0.932 & 0.939 & 0.053 \\
\hline \multicolumn{7}{|c|}{ Mental health worker-school counselor } \\
\hline Configural invariance & 140.155 & 64 & $<0.001$ & 0.928 & 0.949 & 0.054 \\
\hline Metrics invariance & 147.643 & 71 & $<0.001$ & 0.935 & 0.948 & 0.052 \\
\hline Scalar invariance & 159.743 & 77 & $<0.001$ & 0.934 & 0.942 & 0.052 \\
\hline Factor variance invariance & 164.563 & 80 & $<0.001$ & 0.936 & 0.943 & 0.051 \\
\hline \multicolumn{7}{|c|}{ School counselor-call center consultant } \\
\hline Configural invariance & 170.272 & 64 & $<0.001$ & 0.921 & 0.944 & 0.057 \\
\hline Metrics invariance & 186.212 & 71 & $<0.001$ & 0.926 & 0.942 & 0.055 \\
\hline Scalar invariance & 195.456 & 77 & $<0.001$ & 0.930 & 0.940 & 0.054 \\
\hline Factor variance invariance & 203.400 & 80 & $<0.001$ & 0.930 & 0.937 & 0.054 \\
\hline
\end{tabular}

df: degree of freedom, CFI: comparative fit index, TLI: Tucker Lewis Index, RMSEA: root mean square error of approximation

Table 4. Latent mean analysis between the three groups

\begin{tabular}{|c|c|c|c|c|c|c|c|c|c|}
\hline \multirow[b]{2}{*}{ Category } & \multicolumn{2}{|c|}{$\begin{array}{l}\text { Latent mean difference/ } \\
\text { significant probability }\end{array}$} & \multirow{2}{*}{$\begin{array}{c}\text { Cohen's } \\
\text { d }\end{array}$} & \multicolumn{2}{|c|}{$\begin{array}{l}\text { Latent mean difference/ } \\
\text { significant probability }\end{array}$} & \multirow{2}{*}{$\begin{array}{c}\text { Cohen's } \\
\text { d }\end{array}$} & \multicolumn{2}{|c|}{$\begin{array}{l}\text { Latent mean difference/ } \\
\text { significant probability }\end{array}$} & \multirow{2}{*}{$\begin{array}{c}\text { Cohen's } \\
\text { d }\end{array}$} \\
\hline & $\begin{array}{c}\text { Mental health } \\
\text { workers } \\
(\mathrm{N}=270)\end{array}$ & $\begin{array}{l}\text { Call center } \\
\text { workers } \\
(\mathrm{N}=403)\end{array}$ & & $\begin{array}{c}\text { Mental health } \\
\text { workers } \\
(\mathrm{N}=270)\end{array}$ & $\begin{array}{c}\text { School } \\
\text { counselors } \\
(\mathrm{N}=133)\end{array}$ & & $\begin{array}{c}\text { School } \\
\text { counselors } \\
(\mathrm{N}=133)\end{array}$ & $\begin{array}{c}\text { Call center } \\
\text { workers } \\
(\mathrm{N}=403)\end{array}$ & \\
\hline Stress & 0 & $0.150^{* *}$ & 0.68 & 0 & $-0.121^{*}$ & 0.53 & 0 & $0.274^{* * *}$ & 1.10 \\
\hline Resilience & 0 & $-0.406^{* * *}$ & 1.77 & 0 & $0.334^{* * *}$ & 1.24 & 0 & $-0.707^{* * *}$ & 2.83 \\
\hline Burnout & 0 & $2.405^{* * *}$ & 3.67 & 0 & $-1.518^{*}$ & 1.95 & 0 & $3.349^{* * *}$ & 4.19 \\
\hline
\end{tabular}

involve high levels of emotional labor. Our results confirmed that stress had significant direct effects on resilience and burnout, and resilience had significant direct effects on burnout in all groups. The findings support previous research claiming that stress caused by emotional labor can be a cause of burnout, ${ }^{10,32,33}$ implying that call center consultants, mental health workers, and school counselors, whose stress levels are high, will consequently have high burnout levels. Moreover, the findings indicate that, as emotional labor has a higher stress level, resilience, which is a protective factor for regulating and preventing worsening of burnout, will decline considerably., ${ }^{4,153}$ Therefore, to prevent burnout and strengthen the protective factors, stress management programs should be actively developed and deployed, with consideration of the nature of each emotional labor job and also sup- port strategies should be prepared, with consideration of the broader social and economic context factors in the work environment.

Our results are related to the indirect effects of resilience in the relationship between stress and burnout. Partial mediating effects of resilience were found in the call center consultant and school counselor groups, and the indirect effect was not significant in the mental health worker group. The call center consultant case supports previous research results showing that resilience has a mediating effect. ${ }^{13,35}$ Meanwhile, research on the indirect effects of resilience found in school counselors has been absent. Thus, this research is the first to demonstrate that burnout can be relieved by controlling stress levels; it is meaningful in that it confirms that resilience can be a psychological resource in performing emotional labor. 
Therefore, to reduce the burnout of call center consultants and school counselors, promotion strategies to strengthen hardiness, optimism, and patience should actively take place.

For mental health workers, the indirect effect of resilience in the relationship between stress and burnout was shown to be insignificant. This outcome is a divergent finding compared with previous studies on clinical nurses, social workers, and public workers with respect to the indirect effects of resilience found in the relationship between emotional labor stress and burnout. ${ }^{16,36,37}$ However, as mental health workers in this research consisted of 36\% nurses, $57 \%$ social workers, and $8 \%$ clinical counselors, the findings from previous research might not be applicable to this study.

Moreover, in burnout research on psychiatric ward social workers, who have similar emotional labor experiences to the mental health workers in this research, the multiple mediating effects of resilience and social support were proven to be significant, ${ }^{38,39}$ implying that environmental and relationship variables, in addition to psychological factors, play important roles for mental health workers. Therefore, statistical significance may not have been achieved here because this study focused only on the single mediating effect of resilience. Hence, future research should explore emotional labor and burnout in mental health workers, as well as the effects related to the type of mental health agencies and job positions.

Our results are related to the LMA of the major variables. In terms of stress and burnout levels, stress and burnout were highest in call center consultants, followed, in order, by mental health workers and school counselors. Resilience was highest in school counselors, followed, in order, by mental health workers and call center consultants. The effect size of the latent mean difference was highest for burnout, followed, in order, by resilience and stress. Emotional labor showed discrepancies in stress, resilience, and burnout levels across different job sectors.

Call center consultants had the most stress and burnout, and the lowest resilience. This finding is consistent with the results of existing research reporting that this job involves the most emotional labor ${ }^{5,8,32}$ but extends and develops this idea with statistical evidence. Therefore, burnout, which showed the largest latent mean difference, should be prioritized to improve the work environment for call center consultants. Moreover, as call center consultants' had the lowest resilience compared with the other work groups, training programs on psychological persistence and distancing from customer complaints should be developed and deployed. Furthermore, stress and burnout relief methods for people of different age groups, genders, and education levels should be prepared. In addition, obtaining counseling on a regular basis, participating in self-help groups, and running supervision systems are also recommended.
Mental health workers had relatively lower stress and burnout levels and higher resilience compared with call center consultants, but had higher stress and burnout and lower resilience than school counselors. Mental health workers are exposed to active supervision systems and supplementary training. The results indicate that support to reduce job-related stress and burnout and to promote protective factors remains unsatisfactory. ${ }^{910}$ Therefore, the frequency of emotional labor exposure or the number of clients handled under case management should be controlled. Practical and actual strategies need to be formulated in such a way as to reduce the amount of emotional labor.

As a high proportion of workers in these sectors reported experiencing verbal and physical threats at work, their mental health status should be assessed periodically, and professional counseling services should be provided at their workplace. Moreover, governmental efforts to promote job mental health services are crucial. The enactment of the Emotional Labor Worker Protection Act is urgently needed, and call center consultants should be included as a high-risk group for mental health problems, so that systematic adjustments can be made accordingly. In addition, it is also important to develop a job mental health manual for call center workers and provide mental health services in collaboration with regional and basic centers. Trauma prevention and intervention programs should be implemented for mental health workers and school counselors due to clients' violence or suicidal attempts. Psychological support such as debriefing trauma, various coping strategies, and resilience promotion programs should be activated.

The research has the following limitations. First, as the study was limited to a certain area, there are external validity limitations to generalizing the results to a national level. In future research, the study area should be expanded. Also this study is limited in that the gender ratio was not balanced with about $90 \%$ of the study participants being female. It is imperative to remedy this by collecting the samples of male emotional laborers so that gender-based analysis of the psychological characteristics of emotional laborers can be performed in depth. Second, the burnout levels of the subjects in this study were higher than the results of previous studies that used the same scale. ${ }^{7,11,35}$ However, since there are no objective categories for cut-off or severity levels of burnout scale, it may not be valid to determine that the high burnout levels reported in the present study are absolutely serious. Third, this research focused on the indirect effect analysis of resilience as a psychological factor of job burnout; comparative analysis involving environmental factors should be conducted as well. Fourth, age and educational level had significant direct effects on resilience in school counselors and mental 
health workers. These results suggest that demographic characteristics and working conditions, such as salary, work hours, and position, may play important roles in interactions between stress, resilience, and burnout. Therefore, a multi-level model that considers protective factors, actual support systems, and actual workload, as well as both individual (e.g., gender, age, and educational level) and work-environment factors, should be developed to enrich our understanding of this topic. Finally, as this research used a cross-sectional design, longitudinal studies are needed to evaluate issues such as changes in the psychological characteristics of emotional workers over time. Despite these limitations, our study has research implications for proposing theoretical foundations for burnout prevention strategies in different job sectors.

\section{Supplementary Materials}

The online-only Data Supplement is available with this article at https://doi.org/10.30773/pi.2019.07.10.

\section{Acknowledgments}

This study was conducted as part of the Gwangju Mental Health Demonstration Project supported by Ministry of Health \& Welfare and Gwangju Metropolitan city, Republic of Korea. This study was supported by Nambu University.

\section{Conflicts of Interest}

The authors have no potential conflicts of interest to disclose.

\section{Author Contributions}

Conceptualization: Ju-Yeon Lee, Sung-Wan Kim. Data curation: Il-Seon Shin, Jin-Sang Yoon, Sung-Wan Kim. Formal analysis: Yu-Ri Lee. Funding acquisition: Sung-Wan Kim. Methodology: Ju-Yeon Lee, Yu-Ri Lee. Project administration: Yu-Ri Lee, Ju-Yeon Lee, Sung-Wan Kim. Supervision: Jae-Min Kim, Il-Seon Shin, Jin-Sang Yoon. Writing_-original draft: Yu-Ri Lee. Writing_-review \& editing: Ju-Yeon Lee, Jae-Min Kim, Il-Seon Shin, Jin-Sang Yoon, Sung-Wan Kim.

\section{ORCID iDs}

$\begin{array}{ll}\text { Sung-Wan Kim } & \text { https://orcid.org/0000-0002-6739-2163 } \\ \text { Yu-Ri Lee } & \text { https://orcid.org/0000-0002-486-7325 }\end{array}$

\section{REFERENCES}

1. Tsai WC. Determinants and consequences of employee displayed positive emotions. J Manag 2001;27:497-512.

2. Pugh SD, Groth M, Hennig-Thurau T. Willing and able to fake emotion: a closer examination of the link between emotional dis-sonance and employee well-being. J Appl Psychol 2011;96:377-390.

3. Van Dijk PA, Brown AK. Emotional labour and negative job outcomes: An evaluation of the mediating role of emotional dissonance. JMO 2006;12:101-115.

4. Zapf D, Holz M. On the positive and negative effects of emotion work in organizations. Eur J Work Organ Psychol 2006;15:1-28.

5. Brotheridge CM, Grandey AA. Emotional labor and burnout: comparing two perspectives of "people work". J Vocat Behav 2002;60:17-39.

6. Mann S. 'People-work': emotion management, stress and coping. Br J Guid Counc 2004;32:205-221.

7. Wilkerson K, Bellini J. Intrapersonal and organizational factors associated with burnout among school counselors. J Couns Dev 2006;84:440-450.
8. Lewig KA, Dollard MF. Emotional dissonance, emotional exhaustion and job satisfaction in call centre workers. Eur J Work Organ Psychol 2003;12:366-422.

9. Devilly GJ, Wright R, Varker T. Vicarious trauma, secondary traumatic stress or simply burnout? Effect of trauma therapy on mental health professionals. Aust N Z J Psychiatry 2009;43:373-385.

10. Mann S, Cowburn J. Emotional labour and stress within mental health nursing. J Psychiatr Ment Health 2005;12:154-162.

11. Mills LB, Huebner ES. A prospective study of personality characteristics, occupational stressors, and burnout among school psychology practitioners. J Sch Psychol 1998;36:103-120.

12. Dormann C, Zapf D. Customer-related social stressors and burnout. J Occup Health Psychol 2004;9:61-82.

13. Mikolajczak M, Menil C, Luminet O. Explaining the protective effect of trait emotional intelligence regarding occupational stress: exploration of emotional labour processes. J Res Pers 2007;41:1107-1117.

14. Beddoe L, Davys A, Adamson C. Educating resilient practitioners. Soc Work Educ 2013;32:100-117.

15. Kim BN, Oh HS, Park YS. A study of nurses' resilience, occupational stress and satisfaction. Korean J Occup Health Nurs 2011;20:14-23.

16. Strolin-Goltzman J, Kollar S, Shea K, Walcott C, Ward S. Building a landscape of resilience after workplace violence in public child welfare. Child Youth Serv Rev 2016;71:250-256.

17. Kim HJ, Choi HK. The mediating effect of resilience on the relationship between emotional labor and happiness of clinical nurses. Korean J Occup Health Nurs 2017;26:40-46.

18. Park DP, Lee JY. The effects of emotional labor on burnout: The moderating and mediating effects of resilience in child care teachers. JFECE 2016;23:53-70.

19. Cohen S, Kamarck T, Mermelstein R. A global measure of perceived stress. J Health Soc Behav 1983;24:385-396.

20. Lee J, Shin C, Ko YH, Lim J, Joe SH, Kim S, et al. The reliability and validity studies of the Korean version of the Perceived Stress Scale. Korean J Psychosom Med 2012;20:127-134.

21. Mahmut MK, Menictas C, Stevenson RJ, Homewood J. Validating the factor structure of the Self-Report Psychopathy scale in a community sample. Psychol Assess 2011;23:670-678.

22. Jung YE, Min JA, Shin AY, Han SY, Lee KU, Kim TS, et al. The Korean version of the Connor-Davidson resilience scale: an extended validation. Stress Health 2012;28:319-326.

23. Maslach C, Jackson SE. The Measurement of experienced burnout. J Organ Behav 1981;2:99-113.

24. Cole DA, Maxwell SE, Arvey R, Salas E. Multivariate group comparisons of variable systems: MANOVA and structural equation modeling. Psychol Bull 1993;114:174-184.

25. Hancock GR. Structural equation modeling methods of hypothesis testing of latent variable means. Meas Eval Couns Dev 1997;30:91-105.

26. Curran PJ, West SG, Finch JF. The robustness of test statistics to nonnormality and specification error in confirmatory factor analysis. Psychol Method 1996;1:16-29.

27. Aiken LS, Stein JA, Bentler PM. Structural equation analyses of clinical subpopulation differences and comparative treatment outcomes: characterizing the daily lives of drug addicts. J Consult Clin Psychol 1994;62:488-499.

28. Hong S, Malik ML, Lee MK. Testing configural, metric, scalar, and latent mean invariance across genders in sociotropy and autonomy using a non-Western sample. Educ Psychol Meas 2003;63:636-645.

29. Hong S, Hwang MH, Lee ES. Latent means analysis of the Career-Barrier Scale for Korean female adolescents. KJEP 2005;19:1159-1177.

30. Chen FF. Sensitivity of goodness of fit indexes to lack of measurement invariance. Struct Equ Modeling 2007;14:464-504.

31. Cohen J. Statistical Power Analysis for the Behavioral Sciences (2nd Ed). Hillsdale, NJ: Lawrence Erlbaum Associates; 1988.

32. Grandey AA, Kern JH, Frone MR. Verbal abuse from outsiders versus insiders: comparing frequency, impact on emotional exhaustion, and 
the role of emotional labor. J Occup Health Psychol 2007;12:63-79.

33. Andrew Morris J, Feldman DC. The dimensions, antecedents, and consequences of emotional labor. Acad Manag Rev 1996;21:986-1010.

34. Rutter M. Psychosocial resilience and protective mechanisms. Am J Orthopsychiatry 1987;57:316-331.

35. Zunz SJ. Resiliency and burnout: protective factors for human service managers. Adm Soc Work 1998;22:39-54.

36. Kapoulitsas M, Corcoran T. Compassion fatigue and resilience: a qualitative analysis of social work practice. Qual Soc Work 2015;14:86-101.
37. Luthar SS, Cicchetti D, Becker B. The construct of resilience: a critical evaluation and guidelines for future work. Child Dev 2000;71:543-562.

38. Beehr TA, Farmer SJ, Glazer S, Gudanowski DM, Nair VN. The enigma of social support and occupational stress: Source congruence and gender role effects. J Occup Health Psychol 2003;8:220-231.

39. Lim JS, Yoon MS. Moderating effects of ego-resilience, social support on the relationship between secondary traumatic stress and job satisfaction among mental health social workers. Ment Health Soc Work 2014;42:31-60. 
Supplementary Table 1. Descriptive statistics of variables

\begin{tabular}{|c|c|c|c|c|c|c|}
\hline & Minimum & Maximum & Mean & SD & Skewness & Kurtosis \\
\hline Stress & 0.00 & 4.00 & 1.952 & 0.644 & 0.435 & 0.453 \\
\hline Stress 1 & 0.00 & 4.00 & 1.895 & 0.759 & 0.439 & 0.748 \\
\hline Stress2 & 0.00 & 5.00 & 1.873 & 0.825 & 0.457 & 0.529 \\
\hline Stress3 & 0.00 & 4.00 & 2.359 & 0.877 & 0.042 & -0.059 \\
\hline Stress4 & 0.00 & 4.00 & 1.885 & 0.833 & 0.216 & 0.275 \\
\hline Stress5 & 0.00 & 4.00 & 1.748 & 0.865 & 0.392 & 0.126 \\
\hline Resilience & 0.33 & 4.00 & 2.441 & 0.674 & -0.075 & -0.063 \\
\hline Hardiness & 0.00 & 4.00 & 2.284 & 0.755 & -0.047 & -0.085 \\
\hline Optimism & 0.33 & 4.00 & 2.573 & 0.766 & -0.260 & -0.106 \\
\hline Patience & 0.00 & 4.00 & 2.468 & 0.768 & -0.218 & -0.001 \\
\hline Burnout & 6.50 & 35.00 & 20.117 & 5.220 & 0.015 & -0.051 \\
\hline Emotional & 5.00 & 35.00 & 22.523 & 6.169 & -0.257 & -0.273 \\
\hline Cynical & 5.00 & 35.00 & 17.710 & 5.487 & 0.378 & 0.182 \\
\hline
\end{tabular}

SD: standard deviation 


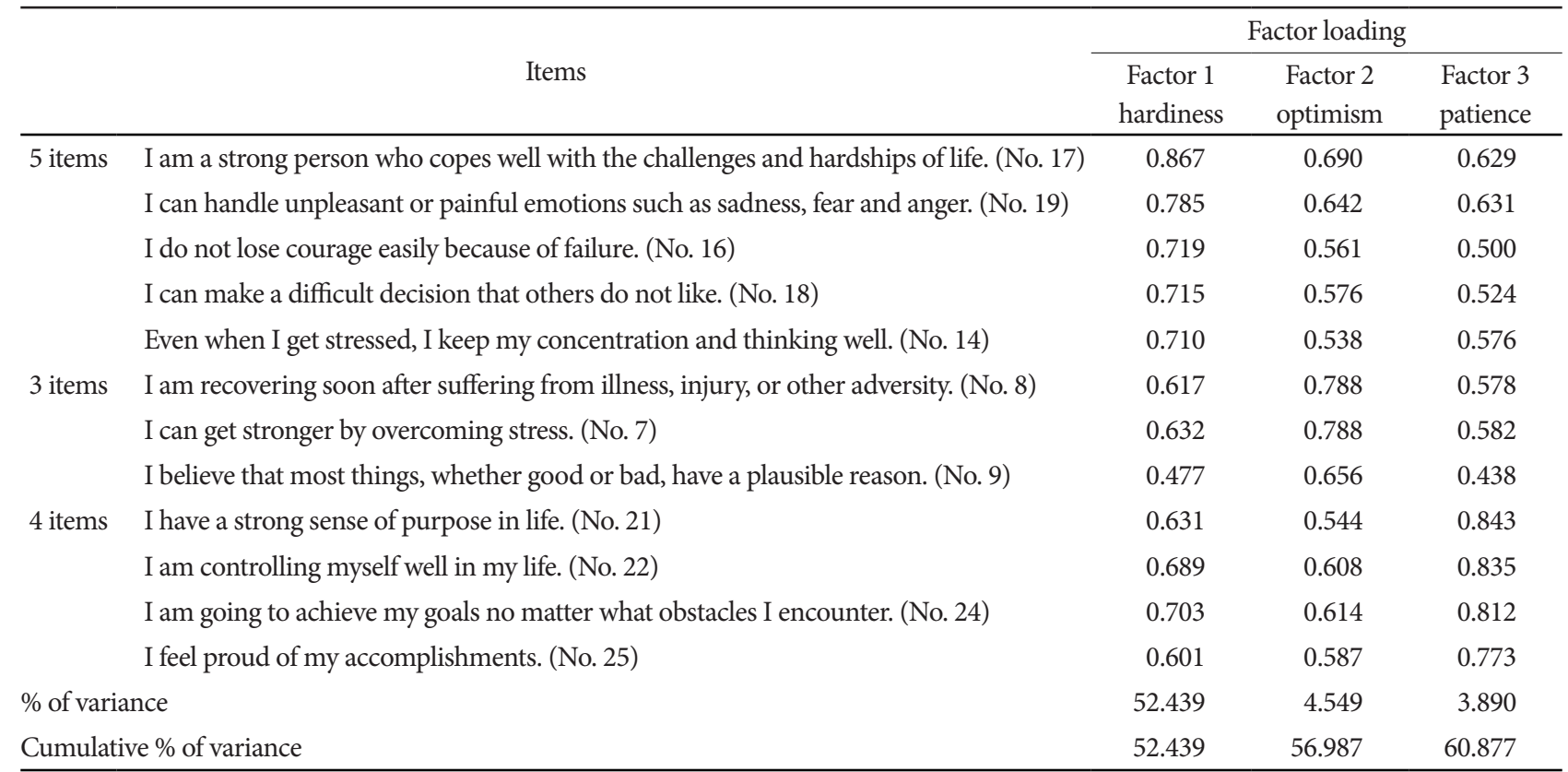


Supplementary Table 3. Confirmatory factor analysis of Resilience Scale

\begin{tabular}{|c|c|c|c|c|c|}
\hline Path & B & $\beta$ & SE & CR & SMC \\
\hline No. $17 \leftarrow$ Hardiness & 1.000 & 0.862 & & & 0.742 \\
\hline No. $19<$ Hardiness & 0.852 & 0.795 & 0.031 & $27.087^{* * *}$ & 0.633 \\
\hline No. $18 \leftarrow$ Hardiness & 0.808 & 0.718 & 0.035 & $23.268^{* * *}$ & 0.515 \\
\hline No. $14<$ Hardiness & 0.791 & 0.707 & 0.035 & $22.774^{* * *}$ & 0.500 \\
\hline No.16 $<$ Hardiness & 0.779 & 0.714 & 0.034 & $23.090^{* * *}$ & 0.510 \\
\hline No.7 $\leftarrow$ Optimism & 1.000 & 0.796 & & & 0.633 \\
\hline No.8 $<$ Optimism & 0.915 & 0.801 & 0.041 & $22.081^{* * *}$ & 0.641 \\
\hline No. $9 \leftarrow$ Optimism & 0.708 & 0.629 & 0.041 & $17.300^{* * *}$ & 0.416 \\
\hline No. $24<$ Patience & 1.000 & 0.827 & & & 0.685 \\
\hline No. $21 \leftarrow$ Patience & 1.019 & 0.820 & 0.038 & $26.949^{* * *}$ & 0.673 \\
\hline No. $22 \leftarrow$ Patience & 0.993 & 0.844 & 0.035 & $28.063^{* * *}$ & 0.713 \\
\hline No. $25<$ Patience & 0.898 & 0.772 & 0.036 & $24.745^{* * *}$ & 0.596 \\
\hline Model fit & \multicolumn{5}{|c|}{$\chi^{2}=200.759, \mathrm{df}=51, \mathrm{TLI}=0.966, \mathrm{CFI}=0.974, \mathrm{RMSEA}=0.060$} \\
\hline
\end{tabular}

*** $\mathrm{p}<0.001$. B: unstandardized estimate, $\beta$ : standardized estimate, SE: standard error, CR: critical ratio, SMC: squared multiple correlation, df: degree of freedom, CFI: comparative fit index, TLI: Tucker Lewis index, RMSEA: root mean square error of approximation 


\begin{tabular}{|c|c|c|c|}
\hline & \multirow[b]{2}{*}{ Items } & \multicolumn{2}{|c|}{ Factor loading } \\
\hline & & Factor 1 & Factor 2 \\
\hline \multirow{7}{*}{6 items } & & & \\
\hline & I am totally exhausted from doing my job. (No. b) & 0.873 & 0.622 \\
\hline & I feel exhausted when I leave work after work. (No. 2) & 0.817 & 0.356 \\
\hline & I feel tired when I get up in the morning and think of going to work. (No. 3) & 0.816 & 0.584 \\
\hline & I feel emotionally exhausted in my work. (No. 1) & 0.755 & 0.442 \\
\hline & Working all day makes me nervous. (No. 4) & 0.730 & 0.460 \\
\hline & I want to work without interruption. (No. 8) & 0.515 & 0.220 \\
\hline \multirow[t]{4}{*}{4 items } & I have a cynical idea that my work is not important. (No. 9) & 0.364 & 0.837 \\
\hline & I have a doubt as to whether my job is important. (No. 10) & 0.453 & 0.828 \\
\hline & My interest in jobs has diminished since I began my current job. (No. 6) & 0.649 & 0.766 \\
\hline & I am passive in my work. (No. 7) & 0.450 & 0.725 \\
\hline \multicolumn{2}{|c|}{$\%$ of variance } & 47.663 & 11.846 \\
\hline \multicolumn{2}{|c|}{ Cumulative $\%$ of variance } & 47.663 & 59.508 \\
\hline
\end{tabular}


Supplementary Table 5. Confirmatory factor analysis of Burnout Scale

\begin{tabular}{|c|c|c|c|c|c|}
\hline Path & B & $\beta$ & SE & CR & SMC \\
\hline No.1<Emotional exhaustion & 1.000 & 0.740 & & & 0.548 \\
\hline No. $2 \leftarrow$ Emotional exhaustion & 1.074 & 0.768 & 0.050 & $21.675^{* * *}$ & 0.589 \\
\hline No.3<Emotional exhaustion & 1.335 & 0.834 & 0.056 & $23.680^{* * *}$ & 0.696 \\
\hline No.5<Emotional exhaustion & 1.356 & 0.891 & 0.054 & $25.276^{* * *}$ & 0.794 \\
\hline No.4<Emotional exhaustion & 1.041 & 0.741 & 0.050 & $20.881^{* * *}$ & 0.550 \\
\hline No.8 $<$ Emotional exhaustion & 0.793 & 0.611 & 0.048 & $17.502^{* * *}$ & 0.425 \\
\hline No. $6 \leftarrow$ Cynicism & 1.000 & 0.777 & & & 0.603 \\
\hline No.9 4 Cynicism & 0.963 & 0.804 & 0.042 & $23.114^{* * *}$ & 0.647 \\
\hline No.10<Cynicism & 1.118 & 0.828 & 0.047 & $23.810^{* * *}$ & 0.686 \\
\hline No.7 $\leftarrow$ Cynicism & 0.854 & 0.733 & 0.041 & $20.895^{* * *}$ & 0.537 \\
\hline Model fit & \multicolumn{5}{|c|}{$\chi^{2}=474.638, \mathrm{df}=27, \mathrm{TLI}=0.894, \mathrm{CFI}=0.902, \mathrm{RMSEA}=0.076$} \\
\hline
\end{tabular}

${ }^{* * *} \mathrm{p}<0.001$. B: unstandardized estimate, $\beta$ : standardized estimate, SE: standard error, CR: critical ratio, SMC: squared multiple correlation, df: degree of freedom, CFI: comparative fit index, TLI: Tucker Lewis Index, RMSEA: root mean square error of approximation 